\title{
Educational Motivation Development by Means of Digital Information and Communication Technologies
}

\author{
Alla Mikhaylova ${ }^{1, *}$, Olga Golovko ${ }^{2}$, and Natalya Nizhneva ${ }^{3}$ \\ ${ }^{1}$ Foreign Languages Department, Sevastopol State University, 299053 Sevastopol, the Russian \\ Federation \\ ${ }^{2}$ Department of Pedagogical Education, Sevastopol State University, 299053 Sevastopol, the Russian \\ Federation \\ ${ }^{3}$ Department of English Linguistics, Belarusian State University, 220030, Minsk, Belarus
}

\begin{abstract}
The article determines the main aspects of educational motivation development by means of digital information and communication technologies. The methodological basis is selfdetermination theory. It is noted that self-determination theory plays a main role in motivation forming. The levels of formation of educational motivation were determined by means of test questionnaire "Research of volitional self-regulation". Based on the data obtained, it was concluded that motivation for learning is a rather difficult and ambiguous process of changing the person's attitude, both to a particular subject of study and an entire educational process.
\end{abstract}

\section{Introduction}

In recent years, there has been a rapid spread of information and communication technologies (ICT) in the field of higher education, in which ICT is considered as a potentially new opportunity to improve the educational process efficiency, and in particular due to stimulating motivation. Lack of motivation is a significant barrier to a success. The low level of goal-directed motivation hinders wellbeing and productivity at last [1]. Some factors influence the motivational level in e-learning, such as the unawareness of the worth, the ability to believe in the effort, and so on.

The digitalization of the higher education system was caused by the social environment with multimedia and information technologies, which implies the presence of high information literacy [2]. It is possible to develop educational motivation and creative thinking of students through the flexibility and variability of the means and methods of their application with the help of ICT [3]. Self-determination can play an important role in people's motivation during professional education, which can help them feel more committed, interested, and satisfied with done things [4].

The difficulty in systematizing knowledge about ways to increase educational motivation in the context of ICT application is the fact that it combines methods, techniques

*Corresponding author: steba1971@mail.ru 
for collecting, transmitting, storing information and methods of interaction in the system of the modern educational process.

In English-language terminology, there are many concepts related to the content of the Russian term ICT, including: technology enhanced learning, computer-based learning digital learning, online learning, multimedia learning and so on [5].

In the theory of educational motivation, there are three approaches to the study of motivation: motivation review in the aspect of external influence and motivation (the concept of external motivation); consideration of motivation as the initial desire of a person to carry out activities for the sake of the activity itself (the concept of internal motivation); theoretical substantiation of motivation without dividing motives into internal and external (or emphasis on their combination) [5].

The methodological foundations of the issue of self-determination were studied by L.S. Vygotsky, V.I. Slobodchikov, S.L. Rubinstein, et al. Relationship between motivation for learning and academic achievement among basic and advanced level students studying a foreign language was considered by $\mathrm{T}$. Li and R. Lynch [6]. C. Sansone's and J.M. Harackiewicz's works deal with an intrinsic and extrinsic motivation 77 Extrinsic motivation was described by Tohidi and Jabbari. Psychological aspects of personality development problem were studied by B.G. Ananiev, K.A. Abulkhanova-Slavskaya. According to J.M. Keller, Attention, Relevance, Confidence, and Satisfaction (ARCS) model is "an approach to instructional design that focuses on the motivational aspects of the learning environment" [8, p.175] by addressing such components of motivation as arousing interest, creating relevance developing an expectancy of success, and increasing satisfaction through intrinsic and extrinsic rewards.

Beata Souders studies the main aspects of motivation in education [9]. "Curiosity and motivation to learn is the force that enables students to seek out intellectual and experiential novelty and encourages students to approach unfamiliar and often challenging circumstances with anticipation of growth and expectation to succeed" [9, www].

We take into account the theory of needs by E. Desi and R. Ryan, which are directed to a sense of competence when performing an activity [10]. They stated that "intrinsic motivation can direct students to participate in academic activities to experience the fun, the challenge, and the novelty away from any external pressure or compulsion and without expectations of rewards" [10, p. 54].

The main aim of the article is to determine the major aspects of educational motivation development by means of digital information and communication technologies.

Foreign researchers note the distinctive features of TED conferences, which set a new vector for the learning process.

\subsection{Materials and methods}

Motivation itself has a vast scope to cater for, and several motivational theories are relevant to e-learning domain: self-determination theory (SDT), intrinsic and extrinsic motivation theory, the ARCS model, expectancy theory, social cognitive theory.

The methodological basis is self-determination theory proposed psychologists Edward Deci and Richard Ryan, who first introduced their ideas in their 1985 book SelfDetermination and Intrinsic Motivation in Human Behavior [10]. They developed a theory of motivation which suggested that people tend to be driven by a need to grow and gain fulfillment. Scientists focused on interdisciplinary connections and integration approaches in the study of the problems of personality self-determination. The methodological basis is the trends in educational psychology as well which draw attention both to cognitive development, and the students' motivation and preference as the fundamental aspects in fostering efficient learning and achievement [4]. 
To determine the level of volitional self-regulation development the test questionnaire "Research of volitional self-regulation" by A.V. Zverkova and E.V. Eidman was used [11].

\subsection{The purpose}

The aim of the article is determines the main aspects of educational motivation development by means of digital information and communication technologies.

The study of volitional self-regulation was carried out with a group of respondents. The respondents were twenty $2^{\text {nd }}$ year students of Maritime Institute, Sevastopol State University. Students of the control and experimental groups were asked to make the instructions. To ensure the independence of the answers of the subjects, everyone receives the text of the questionnaire, an answer form with the numbers of the questions. Instructions contain 30 statements.

\section{Results}

The formation and functioning of the motivational sphere of the student's personality is carried out by the influence of internal psychological factors on it, such as the need for selfaffirmation and recognition, introspection, self-development, etc. [12]

We consider the development of learning motivation from the position of the theory of self-determination, since it is based on three basic psychological needs: autonomy (tendency of lives control, following personal choices and one's own will when making a decision or performing an action); competence (sense of self-sufficiency formation, selfefficiency and progress in the learning process); relatedness (creating a sense of belonging to society, maintaining contacts).

Numerous studies confirm the relevance of this theory and its prevalence over others due to the fact that teaching with the help of ICT is often focused on independent study of educational material.

One of the effective ways of motivation increasing is TED Talks Education which can inspire the students and support educators [13]. TED means Technology Entertainment Design. To explore ideas, TED, WNET, PBS and the Corporation for Public Broadcasting teamed up for a brand-new one-hour special..." [14, www]. TED Talks explore the latest thinking. "Some of the world's greatest educators, researchers, and community leaders share their stories and visions onstage at the TED conference, TEDx events and partner events around the world. You can also download these and many other videos free on TED.com, with an interactive English transcript and subtitles in up to 80 languages. TED is a nonprofit devoted to Ideas Worth Spreading" [14, www].

The intervention program contained a control stage, TED Talks Education and an intervention stage. A control stage included the identification of volitional self-regulation development level by means of test questionnaire "Research of volitional self-regulation". The value of indices of volitional self-regulation is determined by items of the general scale (B) and indices by subscales "persistence" (P) and "self-control" (S) [11].

Each index is the sum of points obtained when calculating the coincidence of the subject's answers with the key of the general scale or subscale.

There are 6 disguises in the questionnaire. Therefore, the total score on "B" scale should be in the range from 0 to 24 , on the "persistence" subscale - from 0 to 16 , and on the "selfcontrol" subscale - from 0 to 13 .

The level of volitional self-regulation $(\boldsymbol{B})$ is referred to a measure of mastering one's own behavior in various situations, the ability to consciously control one's actions, states and impulses. 
The level of development of volitional self-regulation can be characterized as a whole and separately by such character traits as perseverance $(\boldsymbol{P})$ and self-control $(\boldsymbol{S})$.

The levels of volitional self-regulation are determined in comparison with the average values of each of the scales. If they make up more than half of the maximum possible amount of coincidences, then this indicator reflects a high level of development of general self-regulation, perseverance or self-control. Based on the results obtained, we identified the levels (high, medium, low) and presented ones for each scale.

The levels of volitional self-regulation are determined in comparison with the average values of each of the scales. If they make up more than half of the maximum possible amount of coincidences, then this indicator reflects a high level of development of general self-regulation, perseverance or self-control. For " $\boldsymbol{B}$ " scale this value is 12 , for $t$ " $\boldsymbol{P}$ " scale -8 , for " $\boldsymbol{S}$ " scale -6 [11].

A high score of "B" scale is characteristic of people who are emotionally mature, active, and independent. They are distinguished by self-confidence, calmness, stability of intentions, realistic views, and developed sense of their own duty. As a rule, they reflect on personal motives, systematically realize the intentions that have arisen, are able to distribute efforts and are able to control their actions, have a pronounced socially positive orientation. In extreme cases, they may have an increase in internal tension associated with the desire to control every nuance of their own behavior and anxiety about the slightest spontaneity [11].

A low mark is observed in people who are sensitive, emotionally unstable, vulnerable, and insecure. Their reflexivity is low, and the general background of activity, as a rule, is reduced. They are characterized by impulsiveness and instability of intentions. This may be due to both immaturity and a pronounced sophistication of nature, not supported by the ability for reflection and self-control.

The subscale "persistence" characterizes the strength of a person's intentions - one's desire to complete the work, the main value is the project one has begun. Such people are characterized by respect for social norms, the desire to completely subordinate their behavior to them. A loss of flexibility in behavior, the emergence of manic tendencies is possible. Low values on this scale indicate increased lability. The reduced background of activity and efficiency, as a rule, is compensated for in such persons by increased sensitivity, flexibility, ingenuity, as well as a tendency towards a free interpretation of social norms [11].

A high level of the subscale "self-control" reflects the level of voluntary control of emotional reactions and states. It is gained by people who are emotionally stable and have good control over themselves in various situations. Their inherent inner calmness, selfconfidence frees from fear of the unknown, increases the readiness to perceive the new, the unexpected and, as a rule, is combined with freedom of views, a tendency towards innovation and radicalism. At the same time, the desire for constant self-control, excessive conscious limitation of spontaneity can lead to an increase in internal tension, the prevalence of constant concern and fatigue [11].

A low level determines a spontaneity and impulsivity, combined with touchiness and preference for traditional views, protect a person from intense experiences and internal conflicts, and contribute to a calm mood background [15].

The social desirability of high scores on the scale is ambiguous. High levels of volitional self-regulation development can be associated with problems in organizing life and relationships with people. They often reflect the emergence of maladaptive traits and behaviors. Low levels of persistence and self-control in some cases perform compensatory functions. But they also indicate violations in the development of personality traits and her ability to build relationships with other people and adequately respond to certain situations [11]. 
We used TED Talks conferences which provided access to relevant, up-to-date content from various fields of knowledge and perform mission of distributing valuable, unique ideas. Such videos can motivate students and engage them in the new topics study, awakening the enthusiasm for lifelong learning, quenching the thirst for knowledge, personal growth, striving for new experience. TED talks ensure a wide field for rhetorical analysis, allow to answer the question of how effective communication is achieved, what presentation skills are used by the speaker in a particular presentation [16]. The topics of the lectures are very diverse; from medicine and philosophy to art and modern technology, which serve as an emotional, motivational impetus for the processing of the information presented, its assessment, followed by discussion.

TED talks lectures can be considered authentic due to the fact that the speakers are not read the script that was written for them someone, as is often the case with inauthentic texts, but share with the audience their personal experience, captivating ideas, desires and hopes. Since the English language is used in various scientific fields then these are just those possible situations of communication that are as close as possible to life.

An intervention stage is referred to determining volitional self-regulation development level. After the experimental stage which contained TED Talks Education we have analyzed the correlation between changes in educational outcomes. The results showed changes in levels of volitional self-regulation formation (table 1).

Table 1. The correlation between changes in educational outcomes (\%).

\begin{tabular}{|c|c|c|c|c|c|c|}
\hline \multirow[b]{3}{*}{ Level } & \multicolumn{6}{|c|}{ Stage } \\
\hline & \multicolumn{3}{|c|}{ control } & \multicolumn{3}{|c|}{ intervention } \\
\hline & $\begin{array}{l}\text { self- } \\
\text { regulation } \\
\text { (B) }\end{array}$ & $\begin{array}{c}\text { perseverance } \\
\text { (P) }\end{array}$ & $\begin{array}{l}\text { self-control } \\
\text { (S) }\end{array}$ & $\begin{array}{l}\text { self-regulation } \\
\text { (B) }\end{array}$ & $\begin{array}{c}\text { perseverance } \\
\text { (P) }\end{array}$ & $\begin{array}{l}\text { self-control } \\
\text { (S) }\end{array}$ \\
\hline Low & 40 & 50 & 20 & 0 & 20 & 20 \\
\hline Middle & 40 & 25 & 25 & 40 & 30 & 20 \\
\hline High & 30 & 50 & 20 & 60 & 50 & 60 \\
\hline
\end{tabular}

Results from the 5-week intervention program showed that the experiment produced its intended effect and positive benefits: a high level of volitional self-regulation was increased. Recommendations proposed by Kendra Cherry were used to increase motivation $[17,18]$. "It is known that people often feel more motivated when they have control over the situation. One of the main reasons students dislike "group work" is that they lose their individual sense of control and contribution.

To take back control in group interaction students should find a way to make each person feel empowered and influential; do not prevent others from putting forward their ideas; allow group mates to determine what goals they wish to pursue" [7, www].

\section{Discussion and Conclusions}

It was proved that external and internal factors of social self-determination play the main role in educational motivation development. One should use high-quality psychodiagnostic techniques, trainings for motivational growth, aimed at developing skills of selforganization and self-regulation in stressful situations as well.

A set of recommendations were taking into account: “....external and internal factors of social self-determination should be considered in the system, with its inherent connection with the environment, since changes in the social environment entail changes in the system of factors" [4]; high-quality psychodiagnostic techniques and trainings for motivational 
growth in order to form skills of self-organization and self-regulation in stressful situations should be used; it is necessary to provide students' activity [4].

Having received information about the perceived features of self-regulation, it is possible to develop an improvement program, noting those properties that first of all need development or correction.

Form of organization of training in conditions of TED Talks Education, founded on multimedia and information technologies contributes to the development of cognitive skills and educational results, has a positive effect on motivation.

Application of the theory of self-determination made it possible to explain the significant leap in academic performance due to the involvement of all students in the learning process in accordance with the principle of connectedness. Self-regulated learning in the context of e-learning covers such steps as goal-setting, planning, assignment, reflection [17, 19].Motivation is in the form of good grades or recognition, or out of compulsion and fear of punishment [20].

The levels of formation of educational motivation were determined by means of test questionnaire "Research of volitional self-regulation" by A.V. Zverkova and E.V. Eidman.

Based on the data obtained, we can conclude: motivation for learning is a rather difficult and ambiguous process of changing the person's attitude, both to a particular subject of study and an entire educational process.

Diversity of ICT types and ways of their integration into the educational environment and pedagogical activity in the context of TED Talks Education allow designing the interaction environment, and affecting the development of higher mental functions of a person. TED talks lectures provide students with the opportunity to improve their listening skills, note-taking, discussion, critical comprehension of information, which are necessary for communication in the modern world.

\section{References}

1 M.V. Kostsova, A.G. Mikhailova, A.V. Grishina, L.V. Chunikhina, Modern Science. 11-1, 351-35 (2020)

2 I.V. Balynin, A.G. Mikhaylova, N.N. Nizhneva, Vision 2025. Education Excellence Management of Innovations through Sustainable Economic Competive Advantage 34th IBIMA Conference 4477-4490 (2019)

3 A.G. Mikhailova, Vocational, technological and economic training of students in the context of modernization and standardization of education, 73-77 (2020)

4 A.G. Mikhailova, Historical and socio-educational idea 13, 1, 123-133, (2021)

5 T.A. Prudnikova, T.A. Poskakalova, Foreign experience in the use of information and communication technologies in order to increase educational motivation URL: https://cyberpsy.ru/articles/prudnikova-poskakalova-opyt-ikt-v-uchebnoj-motivacii/ (2021)

6 T. Li, R. Lynch, Ascot International School in Bangkok, Thailand, 8, 1. (2016)

7 C. Sansone, J.M. Harackiewicz, S.D., CA, (2000)

8 J.M. Keller, Distance Education, 29, 175-185. (2008)

9 B. Souders. Positive Psychology, URL: https://positivepsychology.com/motivationeducation/ (2021)

10 R.M. Ryan, E.L. Deci, Contemporary Educational Psychology 25, 54-67, (2000)

11 Research of Volitional Self-regulation by A.V. Zverkova and E.V. Eydman URL: http://testoteka.narod.ru/lichn/2/05.html (2021)

12 Yu.E. Vodyakha, Psychological diagnostics of personality spheres, (2018) 
13 TED Talks Education, URL: https://www.ted.com/about/programs-initiatives/tedtalks-education (2021)

14 TED Talks Education, URL: https://podcasts.apple.com/us/podcast/ted-talkseducation/id470623037 (2021)

15 A.G. Mikhailova, O.N. Golovko, International scientific journal, 2, 34-37 (2020)

16 I.N. Kosheleva Video Materials Tedtalks as an Educational Tool in Teaching English at a University 5 (118). 13-14 (2017)

17 Cherry Kendra, Self-Determination Theory and Motivation. URL: https://www.verywellmind.com/what-is-self-determination-theory-2795387 (2019)

18 Cherry Kendra, 5 Surprising Ways to Get Motivated. Psychological techniques to help you get more motivated. URL: https://www.verywellmind.com/surprising-ways-toget-motivated-2795388 (2020)

19 A.E. Courtney, MSc. Self-Determination Theory of Motivation: Why Intrinsic Motivation Matters. URL: https://positivepsychology.com/self-determination-theory/ (2021)

20 H. Tohidi, M.M. Jabbari, Procedia-Social and Behavioral Sciences, 31, 820-824 (2012) 